\title{
Nations urged to unite on drilling costs
}

Munich. Plans are being drawn up for an International Scientific Continental Drilling Programme (ICDP) which geophysicists hope governments will agree to support as a way of sharing the costs of drilling and operating boreholes in different parts of the world.

One project that could benefit from such an international programme is a proposal from US scientists to drill a hole of at least $10 \mathrm{~km}$ into the San Andreas Fault to study the mechanisms of earthquakes.

Supporters of the ICDP point out that, as well as revealing knowledge of the Earth's crust, drilling also provides information about natural phenomena which have a direct impact on society, such as the origins of earthquakes, mechanisms of climate change and possibilities for the safe geological disposal of hazardous waste.

But continental drilling, particularly at great depths, is both expensive and technologically challenging. As a recent report to the Megascience Forum of the Organization for Economic Cooperation and Development pointed out, there is therefore a strong case for international cooperation.

Scientists and representatives of funding bodies from 13 countries met in Potsdam last month to discuss how this cooperation might be achieved by the proposed ICDP. The meeting agreed that a science programme should be drawn up for such a programme by a committee of scientists from ten countries. This will form the basis for negotiations for funding from individual countries, as well as from potential international bodies such as the European Science Foundation and the European Communities.

The structure of the ICDP itself remains to be determined. Mark Zoback, professor of geophysics at Stanford University and a member of the ICDP committee, says that one possible model is the US-led Ocean Drilling Program (ODP).

Under the ODP model, any country wishing to participate would pay a basic fee to cover administrative staff, the costs of drilling, and for some scientific projects. Research teams would then apply either individually or jointly for project money, and their applications would be assessed by expert panels.

Germany, which has long experience of scientific continental drilling, is expected to lead the ICDP. A national geological sciences research centre has been set up in Potsdam, and the centre has already offered at least one staff member to help develop the initial planning of the ICDP.

Germany began its own drilling programme, known as the KTB (Kontinentales Tiefbohrprogram) 15 years ago at a site in northern Bavaria. The hole is now $8.3 \mathrm{~km}$ deep, and should reach $10 \mathrm{~km}$ by the end of the year. This is the depth at which the heat is such that rocks become plastic and are unable to transmit mechanical forces.

ICDP committee member Rolf Emmermann, who is both head of the geosciences research centre and a scientific director of the KTB, says that discussions are already taking place with the ministry of research about keeping the borehole open for a further two years as a deep-crust laboratory. One proposal is that scientists from other countries should be asked to pay to use the proposed laboratory for their own experiments.

According to Emmermann, an international programme is justified not merely on the basis of cost-saving but also because many of the questions that boreholes can answer are global both in nature and in their importance to society. If the ICDP takes off, Emmermann says he hopes that the German government would agree to release the KTB drilling equipment for other projects, such as that to drill into the San Andreas Fault.

In the past, deep drilling has been criticized by some geoscientists who use other techniques to study the Earth's crust on the grounds that it provides data about a very limited area at a very high price. The ICDP

France's Institute for
Marine Research
(IFREMER) last week
launched its new
research vessel
L'Europe. The institute
has chosen a catama-
ran design for stability
and convenience when
lowering scientific
instrumentations
directly into the water.
L'Europe will carry out a
wide range of missions,
including the study of
fisheries resources, and
seismic and echo-
sounding operations.

is likely to cost at least US\$40 million a year. But Rolf Meisner, a seismologist at Kiel University in Germany, claims that it takes the public and political appeal of 'big science' projects, such as the proposal to drill into the San Andreas Fault, to generate this sort of money.

Alison Abbott

\section{Institute will act as 'brain centre' of Japanese science city}

Tokyo. Japan's International Institute of Advanced Studies (IIAS) opened last week in plush new surroundings in the hills between Osaka, Kyoto and Nara. The institute, intended as the 'brain centre' of the Kansai Culture and Science City that is slowly emerging between the three cities, is headed by Michio Okamoto, a former president of Kyoto University, and is modelled on the Princeton Institute of Advanced Studies in the United States.

For the past several years, the institute has been occupying temporary headquarters in Kyoto. Local prefectural governments and private sector institutions have now injected billions of yen into providing it with land and the new building. The institute now includes a Japanese garden where scholars can contemplate the future of science and society.

The Kansai science "city" that it will serve is at present just a handful of isolated institutes in the mountains. But the city is expected to have a population of nearly 400,000 people when completed next century after an estimated investment of US\$25 billion.

IIAS hopes to invite leading scholars from all over the world to carry out research, most of which will be theoretical, with experimental work being carried out separately in universities or research institutes. There will be three projects on the theme of "theoretical life science", and another project will focus on the concept of "safe science".

The founders of IIAS were initially successful in raising funds from the private sector and local governments in the late 1980 s and early 1990s when Japan's economy was booming. But fund-raising has since run into difficulties because of the recession.

Annual interest from the existing fund is only about $¥ 150$ million ( $\$ 1.5$ million), but IIAS needs about $¥ 500$ million a year to cover its operating costs. An institute official says that it has enough funds to last for about two years. Its survival beyond that will depend on its success in raising funds from government agencies and the private sector.

David Swinbanks 